\title{
Innovation within Small-Medium Scale Contractors in Indonesia
}

\author{
Rizal Bahaswan*1, Zulaicha Parastuty², Ani Wulandari', Sri Wiwoho Mudjanarko ${ }^{1}$ \\ ${ }^{1}$ Narotama University, Surabaya - Indonesia \\ ${ }^{2}$ Alpen-Adria University of Klagenfurt, Austria \\ rizal.bahaswan@narotama.ac.id, parastuty@gmail.com, ani.wulandari@narotama.ac.id, \\ sri.wiwoho@narotama.ac.id
}

\begin{abstract}
In order to survive within the industry, small-medium scale contractors are required to be adaptive. However, many obstacles have been experienced by this group to deal with. The term of survive can be interpreted by doing continuous innovation. This research was conducted to investigate the innovation issues related which possibly could triggering or canceling the innovation within small-medium scale contractors. Literature study was conducted as a primary and followed by a field research using questioners. From the research it was found that the main motivation and orientation within innovation processes was the competitiveness among the group of contractors and followed by the attempt to respond the recently industry environment. However, they tend to avoid the change in their business concept. Finally, the availability in source of funding was highlighted as the main factor which might brough innovation initiative successful.
\end{abstract}

Keywords: Small-medium Scale Contractors, Innovation.

\section{INTRODUCTION}

The important role played by small and medium-scale construction companies has faced many obstacles. This condition has been brought to the attention of the government and professional bodies. A number of recommendations and theories have been introduced to the industry in order to solve this deficiency. One of the major concerns in this subject is the innovations that small-medium scale construction companies may do in order to succeed in the industry. Despite the assistances from the government and donor agencies, which in many cases are deliberated in facilities and equipment, the ability of the companies to manage such assistance and the occurred change is more important. In many researches, enough evidence shows that the lack of managerial skills has led to small-medium scale construction companies facing the insolvency [for examples, see Eyiah and Cook, 2003; Eyiah, 2001; Hayashi, 2002; Kaming et al, 1997].

On the other hand, there are characteristics noted by Handayani [2017] regarding this group of companies. Delay in project compilation, over budget, over using resources, and construction waste are some of areas where they have been lacking for. Another concern regarding this subject is that they only concern to its instant profit and it should be automatically generated after winning a project tender at any winning bidding price.

Moreover, surprisingly the Indonesian construction industry tends to become a high cost industry because of a lot of unofficial spending occurs within the process of construction. Referring to Suwandono (2004), the bleeding in the industry is around $50 \%$ from the total industry value and most of it is spend on administrative purposes. Furthermore, the inefficiency within the industry is also caused by the lack of interrelation between aspects within the industry structure. These are; 1) physical elements (the construction output); 2) legal artifacts (legal aspect which is provided by the government in order to bring a good environment to the industry); and 3) scientific (the players within the industry, 
such as innovators, motivators and aspirators). It has been noticed that there is a remaining gap and it tends to be a barrier between professionals (construction practices) and academics which makes endeavors within the industry difficult to achieved (www.pu.go.id (a)].

\section{LITERATURE REVIEWS}

The term of innovation has noticeably emerged into the industry since 1990's when a series of studies were conducted by the UK government through its professional bodies. Two well-known reports, The Latham report (1994) and The Egan report (1998), are believed have to brought significant improvement to the industry [Briscoe, et al, 2004, Fairclough, 2002].

In general, there are a number of ways where innovation in the construction industry can be achieved. Blayse and Manley (2004) wrote a significant paper related to this topic. They define innovation by referring to Oslo Manual under the 'technical' and/or 'organization' headings of innovation. The technical innovation relates to the products and processes, whereas organization innovation deals with something like, new corporate strategy, organizational structure and advance management techniques.

However, the construction industry tends to operate in a dynamic environment and having tight competition amongst others. This condition increases pressure for the firms who have the same size, scope and standing. A result of this is, that they tend to have the same strategic group behavior. Hence, in order to struggle, the firms are normally motivated to do such innovations [Moodley and Preece, 2003].

Furthermore, referring to Hamel [2000], Moodley and Preece wrote that in a dynamic economy, the changing to business concept is the most appropriate way of conducting such an innovation. In many cases, this business concept can be deemed as the business model, which is simply understood as being the manner in which the concept is put into practice.

Another school of thought on innovation was presented by Eaton [2001]. He introduced the developing of innovation typology which concentrates more on the context of innovation rather than the content. He argues that the proposed typology presents an evolutionary (rather than revolutionary) framework for the presentation of innovation by strategy.

Eaton argues that innovation theory can be approached by using two terminologies, "innovation epochs" and "innovation mechanisms". Those terminologies are not a sequence of innovation processes. Innovation epochs consist of elements that build innovation mechanisms. Therefore, it is important to distinguish and understand the definition of both of them.

In the heading of innovation epochs, he identifies four epochs, which are; 1) Factor conditions; 2) investment; 3) innovation; and 4) wealth. Furthermore, Eaton explains that innovation processes can take place at any point within the temporal development of an organization. It can start with the new exploitation of existing factor resources within the factor condition epoch, ensuing through the investment epoch, the investment epoch and finally completing a disperse of organization units within the wealth epoch.

Besides the four epochs of innovation mentioned above, Eaton has also described innovation mechanisms. These mechanisms were inspired the research of former authors who based their work on the biological sciences and in particular, work on biological evolution. There are five mechanisms of innovation that have been identified, which are; 1) Standard canalization evolution of innovation; 2) Neotenic evolution of innovation; 3) Pyrogenetic evolution of innovation; 4) Parasitic evolution of innovation; 5) B-Z oscillatory evolution of innovation.

After knowing the definition of innovation under the heading of the construction industry and some mechanisms that have been used, it is important to understand what factors can significantly 
determine the pace and route of conducted innovation. Blayse and Manley [2004] summarized that there are six factors that influence innovation in the construction industry, which are; a) Clients and manufacturers, b) The structure of production, c) Relationships between individuals and firms within the industry or between the industry and external party, d) Procurement systems, e) Regulations/standards, f) The nature and quality of organizational resources.

Therefore, in respect to the overview above, it is important to put a line about guidance for the small and medium-scale construction companies in innovation for their management endeavor. It is more like a literature synthesis which might bring ideas of the direction of innovation that small and medium-scale construction companies might have. It was Sexton and Barrett [2003] who started their research with questions taken from CIC/DoE in 1996, which were: a) What is the motivation to innovate? b) What is appropriate innovation, how can an individual firm and the supply chain innovation be integrated? and c) How can innovation be successfully implemented?

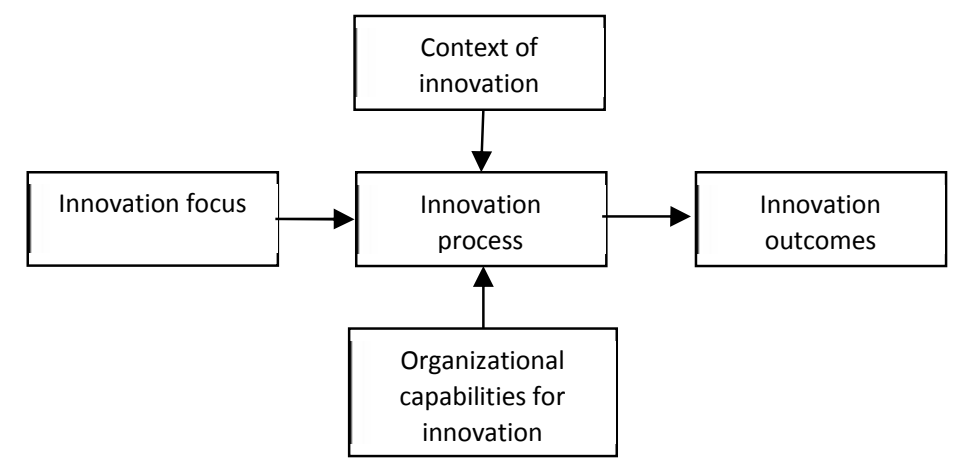

Figure 1. The generic innovation model [Sexton and Barrett, 2003]

\section{METHODOLOGY}

The field research will be conducted using questionnaires distributed to the selected respondents. The data will be collected through questionnaire structured qualitatively. The arising questions will be structured based on the issues from the literature review and formulated with the key questions of the research. In general, the questions can be grouped into two sections. First, it will identify the general information about the company and second, it will investigate the current position of the firms regarding the innovation theories. The populations used in this research will be concentrated to selected small and medium contractors located in East Java (Jawa Timur), Indonesia.

This research will be conducted by e-mailing the questionnaire to the respondents. The questionnaires will be filled in by the chosen respondent from those small and medium firms. Based on pilot investigations, the respondents are persons who have the capability of deciding the firm's policies and who have a good knowledge of the subject researched. They might be the firms' director, head of the development division and other senior employees. The primary research, which was unstructured interviews, has been conducted using selected respondents before the questionnaire was distributed. This helps respondents to understand the research subject and avoid bias when answering the questions [Naoum, 1998].

Since the questionnaire was constructed using qualitative questions or open-ended questions, each question will be analyzed individually. The answers will be compared amongst others and the structure documented. Patterns will be expected for each of the answers. The use of graphs and charts will give better overviews of the answers 


\title{
RESULT AND DISCUSSION
}

\section{Result}

As has been explained in methodology, the questionnaire consists of two main categories, which are; general information of the company and innovation within the company. At this stage, each enquiry will be discussed separately, and an analysis will be conducted to identify and describe the patterns of the received questionnaires.

\section{A. General Information section}

This category consists of eight questions. The results can be described as following;

\section{Question 1,2,3,4 and 5:}

\author{
Name of the company \\ Current position of the respondent \\ Year of establishment \\ What is the main work undertaken over the last 5 years? \\ Membership of association bodies
}

Results; There were two types of company ownership within the respondents, which are private or individually owned companies and share owned companies. It is important to point out that this classification does not always verify the scale and capability of the companies. Yet, the shared owned companies may have more sources which automatically increases their ability compare to private owned companies. Furthermore, in respect of company size, the majority of respondents are classified as small-scale construction company.

Under the heading of works undertaken, the majority of the small-scale companies have a general classification. It means that they do not have a specification of works undertaken and most of the time they act as sub-contractors depending on the available work given to them by main contractors. On the other hand, medium scale enterprises have acted as main contractor on most of their projects.

Almost all of the respondents are registered to more than one professional body. This is because, usually, for following certain tenders, membership to one particular association is obligatory. However, there is one company who is not registered in any of the professional bodies. It may happen because the company can be classified as a home industry and most of the time, it gets the contract by direct reference from the main contractors.

Question 6: In brief, how is the position of your company's assets over the last 5 years?

Results: In general, the small-scale enterprises experience more inconsistency compared to the medium scale enterprises. Even though there were increases, it depended more on the availability of the work undertaken by the companies. In other words, the nature of unspecified work undertaken, as has been discussed before, makes them not want to invest on certain equipment and prefer to have deposits of money which can be used more flexible. On the other hand, increased assets were shown by the medium scale construction firms with the investment on new equipment, facilities (i.e. operational cars, office stationeries, etc.), and office building/workshop.

Question 7: In your opinion, what are the problems facing the industry?

Results: From the seven aspects presented to the respondents, there are two elements that are underlined as the most problematic in the industry with $19 \%$ each. These are the sources of funding and the government policies. The unhealthy competitiveness environment comes after with $15 \%$ followed by unhealthy organization structure with $14 \%$. The rest of the headings, which are inefficiency in production processes, human resource problems and short of equipment, follow with $13 \%, 10 \%$ and $9 \%$, respectively. 


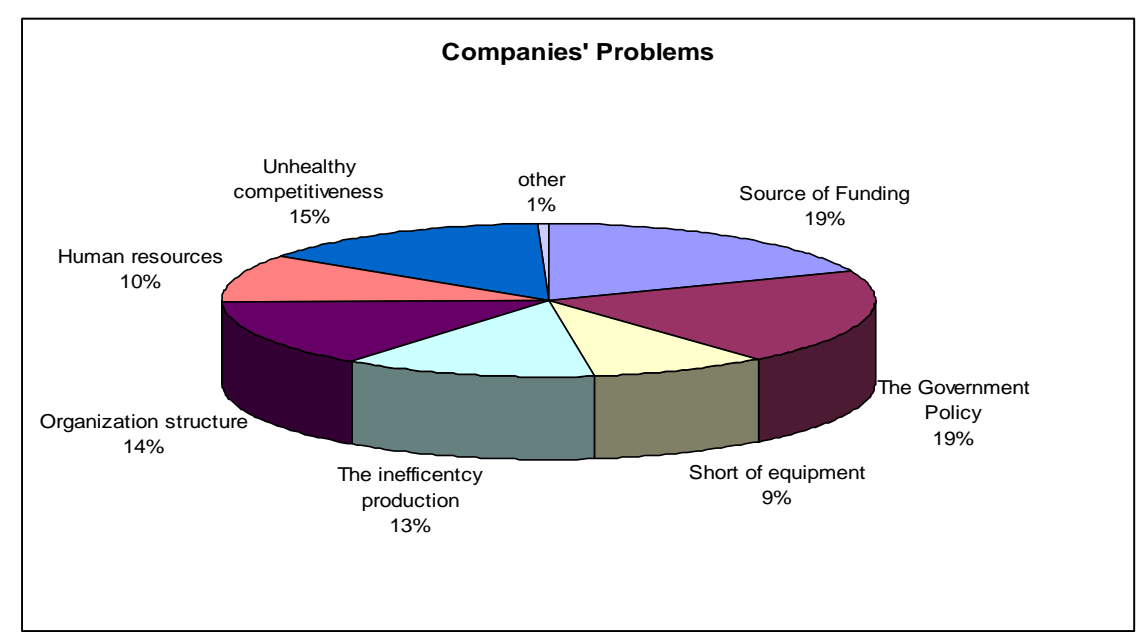

Figure 1. The problems faced by the Indonesia construction industry

Question 8: Indonesian economic has been experienced several crises period during last 20 decade, Was the recently economic crisis still affecting the industry?

Results: The majority of the respondents argued that every experienced economic crisis are affecting the industry. Yet, the remain of the respondents who answered 'no' are small scale enterprises. This is because these companies were established after the crisis period, thus they did not experience the massive downturn in the economy, while other argues that the company's market is relatively steady because of its specialized products. Some also argue that due to the crisis the innovation processes within the industry are worse than previously. Before the economic crisis, the tender mechanism would sometimes consider the innovation offered by contracts despite the lowest cost selection mechanism. This has been the only criteria of winning such tenders ever since.

\section{B. Innovation within the company section}

This category consists of seven questions. The results can be illustrated as follows;

Question 9: With the current position of the company, is the innovation process needed?

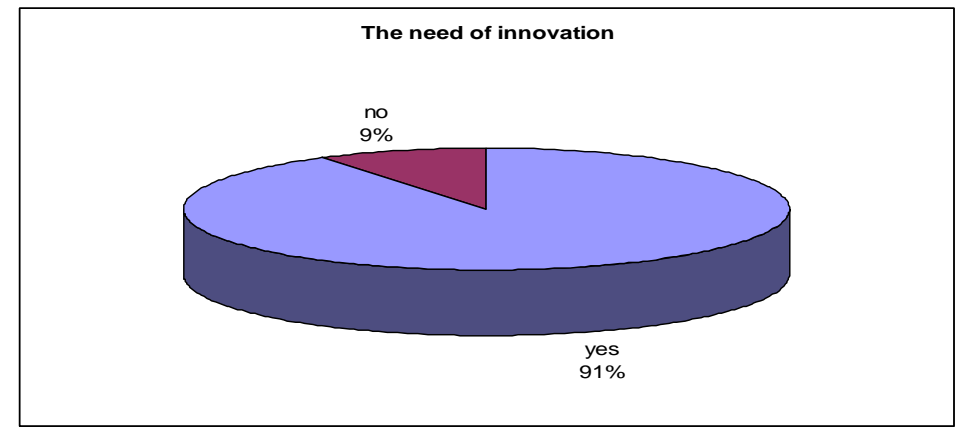

Figure 2. The need of innovation within the firms

Results: Almost all of the respondents agreed that the innovation process is needed within their companies (91\%). Even though they have diverse descriptions of the meaning of the needed innovation, it seems that all respondents underline that innovation process is necessary in order to take over the competition in the tight industrial environment. On the other hand, it is noted that human resources are the area where the innovation needs to be enforced.

Question 10: In your opinion, what are the triggering moments/situations which stimulate the company to conduct such an innovation process? 
Results: Since the enquiry is an open-ended question, the answers gathered from the questionnaires are varied. Yet, it can be highlighted that the major events which stimulate innovation are; the awareness of new competitors, the facilities provided by the government regarding the opportunity to do such innovations, new technology and information, the stability of the national economy and politics and last, the willingness of maintaining companies' reputation. Nevertheless, within this particular enquiry, these aspects did not come either as a sequence or correlation among others.

Question 11: If the innovation processes would be necessary, in what way will it take place?

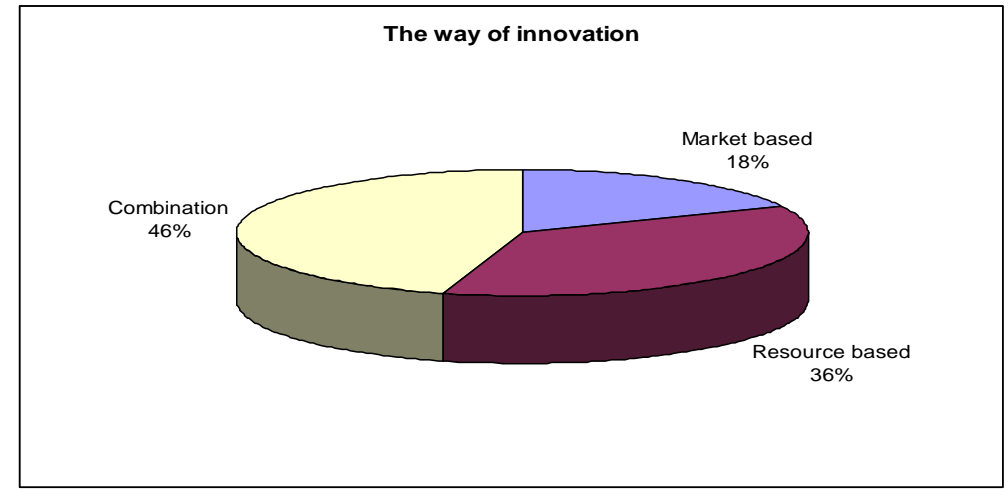

Figure 3. The way of innovation process undertaken

Results: Almost half of the respondents (46\%) argued that a combination between market based and resource-based innovation is the most appropriate way conducting such innovations. The main reason for choosing this option is to optimize the processes. They realize that it is important to respond to the shifting market and update their processes according to the present condition. However, it will be useless if the biggest flaw is coming from the inside organization itself. This may lead to innovation becoming a pointless process.

However, another concern is that resource-based innovation will be more appropriate because it may be more economic and less risky compared to others. Whilst, the market-based innovation has been chosen for the companies who already feel secure and confident with their ability to challenge the competitors. This option was chosen by medium scale contractors who have been existing longer and have a relatively more stable organizational structure compared to the others.

Question 12: In your opinion, is it necessary to change the business concept within the innovation processes?

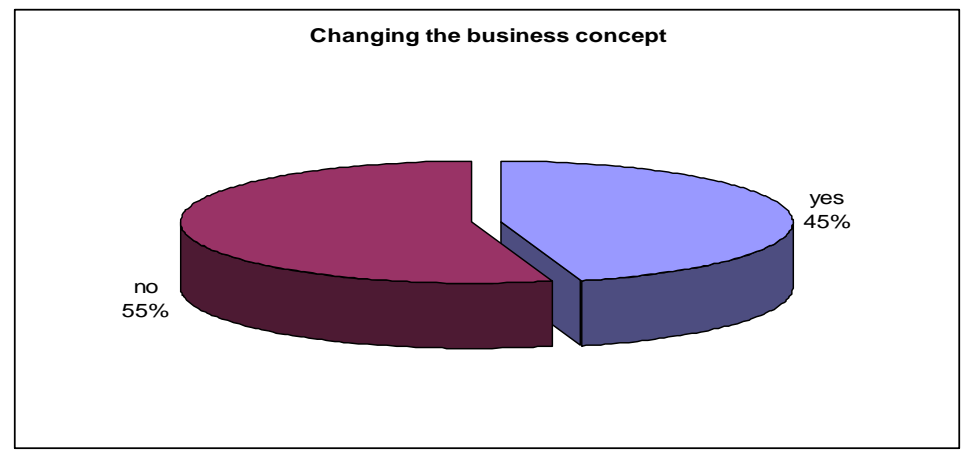

Figure 4. The need of changing business concept within innovation

Results: $55 \%$ of the respondents do not want to change their business concept, where the majority respondents in this category are small scale firms. They argue that any major shifting within 
their business concept will bring a major alteration in the business mechanisms which will be automatically followed by the increasing of risks. This has been supported by the fact that small scale enterprises tend to have a more limited market which makes them have less options compared to the others (question no 5). Yet, this process might be possible for bigger enterprises because they are fairly more immune and have excess of resources. It may be useful to support the firms' position during the execution of the innovation processes.

Question 13: When conducting the innovation process, does your company need assistance from other bodies?

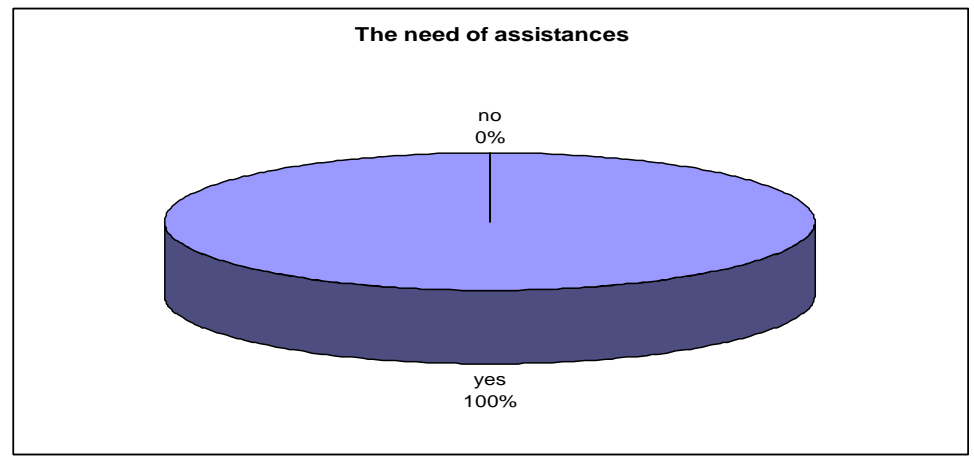

Figure 5. The need of assistances from other bodies

Results: All of the respondents agreed that in order to achieve a successful innovation processes, the assistance from other bodies is required. Yet, the role played by those bodies may be varied. The majority of the medium scale contractors view the assistance as example and reference on where the innovation may lead to. However, a different opinion was formulated by the majority of small contractors, who expect more active assistances. The assistances might be special programs specially designed to boost the processes. Vigorous contributions are expected from the government or other bodies who are responsible for the industry.

Question 14: In your opinion, what is the sequence of the influential factor within the innovation?

Results: it was noted that the capability, which in this case is the firms' resources, is the most influential factor determining the innovation process within the respondents' firm (25\%). The tender system scored second with $20 \%$ and it is followed by the government policies in third (16\%). With only a slight difference, clients and supplier factors and production structure follow with $15 \%$ and $13 \%$ respectively. Finally, related issues only contribute less than $10 \%$.

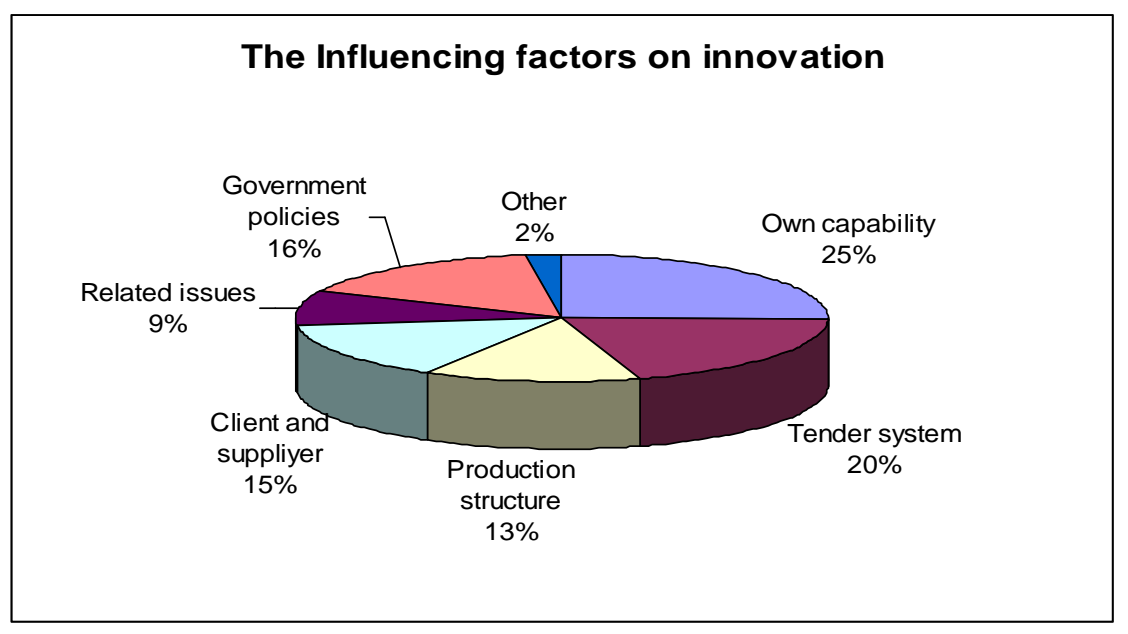

Figure 6. The influencing factors on innovation process 
Question 15: What is the major constrains for the company conducting the innovation?

Results: Basically, this question summarizes the discussion regarding the innovation processes within the small and medium scale construction firms. As has been documented previously, the results regarding this enquiry emphasizes the areas which need to be highlighted. Those areas are; the provision of funding assistance, human resources, supported government policies and conducive environment that maintains the sustainable processes.

\section{Discussion}

The Indonesian construction industry has been suffering from the down turn of the economy, especially during the economic crisis. It has changed the fundamental structure of the industry including the pace of the innovation processes. The data collected from the questionnaires indicate that there are different patterns between the small and the medium scale construction companies regarding the innovation processes. Yet, regarding this discussion, the innovation process can be looked at from its means, direction and influential factors.

The terminology of innovation has become a topic of discussion within the industry since many studies indicate its inefficiency. This condition has also occurred within the Indonesian construction industry. However, the attractive industry environment has been affected by many economic crises. The innovation term, which is normally connected with the extra budget and series of research which absorb a lot of firms' resources, has been replaced by the term off 'low budget' or 'the lowest tender value'. This condition has brought the innovation back to the early stage of its development.

The recovery of the Indonesian economy has dragged many enterprises within the industry to survive during the crisis. Yet, the enterprises tend to choose 'investing' rather than 'innovating'. They prefer to have set of assets rather than a risky investment (which in this case is innovation). Regarding this issue, the research finds that medium-scale firms have a tendency to invest on office facilities (buildings, cars and other office facilities), while small-scale firms tend to put some reserves in the bank.

On the other hand, the current condition of the industry does not shrink the firms' willingness to conduct innovation in order to improve and solve the problems. Even though a major concern comes from the external factors of the industry (financial structure and government policies), it is important to improve its internal factors, which have been noticed to contribute to the downturn of the industry.

\section{CONCLUSION}

Concerning the analysis of the motivation and orientation of innovation, the research has found that the competitiveness amongst construction firms seems to be the highest motivator to the event. It is followed by an attempted response to the changing on the industry's environment. Moreover, the industry tends to combine the market based and resource-based innovation, which will arguably lead to more effective innovation processes. Yet, it seems that the contractors will avoid radical changes in the innovation processes by not changing the business concept of the companies.

Finally, the success of the innovation process within the industry is mainly determined by the availability of resources within the companies. The research underlines that any attempt to improve the general industry performance, must firstly improve the firms' ability and resources before dealing with other external factors. Regarding this, the development of human resources and provision of supported sources of funding are stressed by the majority of the respondents.

\section{REFERENCES}

Blayse A, M; Manley, K; [2004]; Key Influence on Construction Innovation; Construction Innovation; 4th; p 143154 
Briscoe, D, R; et al; [2004]; International Human Resources Management; Routledge; New York; $2^{\text {nd }}$ edition

Eaton, D; [2001]; A Temporal Typology for Innovation within The Construction Industry; Construction Innovation; 1 st; $p$ 165-179

Eiyah, A, K; Cook, P; [2003]; Financing small and medium-scale contractors in developing countries: a Ghana case study, Journal of Construction Management and Economics, no 21, p 357-367

Handayani, F, S,: [2017]; Strategy for Small-Medium Scale Contractor Performance Improvement in ASEAN Competitive Market; Procedia Engineering; 171 ; $p$ 387-395

Hayashi, M; [2002]; The rule of subcontracting in SME development in Indonesia: Micro-level evidence from the metal working and machinery industry, Journal of Asian Economic, no 13, p 1-26

Kaming, P, F; et al; [1997]; Factor Influencing Construction Time and Cost Overrun on High Risk Projects in Indonesia; Journal Construction Management and Economics; Vol 15, issue 1

Moodley, K; Preece, C; [2003]; Construction Business Development; Elsevier; Oxford-England; p 7-16

Naoum, S, G; [1998]; Dissertation research and writing for construction students, Butterworth-Heinemann, Oxford

Sexton, M; Barrett, P; [2003]; A literature synthesis of innovation in small construction firms: insights, ambiguities and questions, Journal of Construction Management and Economics, no 21, p 613-622

Fairclough, Sir, J; [2002]; Rethinking Construction Innovation and Research - A review of government R\&D policies and practices; DTLR; www.dti.gov.uk/construction

Suwandono, D.; (2004); Suara Merdeka; Online newspaper; 70\% Dana Konstruksi Bocor-70\% of Construction Budged is Dislocated; http://www.suaramerdeka.com/harian/0402/12/eko6.htm; $19^{\text {th }}$ of July 2005

www.pu.go.id (a); NSPM (Norma Standart Pedoman Manual) Perlu Dipahami Secara Proposional-Standard Guidance Manual is Needed to be Understood Properly; Online Journal; http://www.pu.go.id/bapekin/buletin\%20jurnal/buletin\%204/buletin41.html; $19^{\text {th }}$ of July 2005

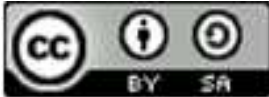

(C) 2020 by the authors. Submitted for possible open access publication under the terms and conditions of the Creative Commons Attribution (CC BY SA) license (https://creativecommons.org/licenses/by-sa/3.0/). 